\title{
The Association between a History of Parental Addictions and Arthritis in Adulthood: Findings from a Representative Community Survey
}

\author{
Esme Fuller-Thomson, ${ }^{1,2}$ Jessica P. Liddycoat, ${ }^{2}$ and Maria Stefanyk ${ }^{2}$ \\ ${ }^{1}$ Sandra Rotman Endowed Chair, Department of Family \& Community Medicine, Toronto, ON, Canada M5S 1A1 \\ ${ }^{2}$ Factor-Inwentash Faculty of Social Work, University of Toronto, 246 Bloor Street West, Toronto, ON, Canada M5S 1A1 \\ Correspondence should be addressed to Esme Fuller-Thomson; esme.fuller.thomson@utoronto.ca
}

Received 12 October 2013; Revised 24 January 2014; Accepted 30 January 2014; Published 23 March 2014

Academic Editor: Sally Guttmacher

Copyright (C) 2014 Esme Fuller-Thomson et al. This is an open access article distributed under the Creative Commons Attribution License, which permits unrestricted use, distribution, and reproduction in any medium, provided the original work is properly cited.

\begin{abstract}
Aims. To examine the relationship between a history of parental addictions and the cumulative lifetime incidence of arthritis while controlling for age, sex, race, and four clusters of risk factors: (1) other adverse childhood experiences, (2) adult health behaviors (i.e., smoking, obesity, inactivity, and alcohol consumption), (3) adult socioeconomic status and (4) mental health. Materials and Methods. Secondary analysis of 13,036 Manitoba and Saskatchewan respondents of the population-based 2005 Canadian Community Health Survey. Sequential logistic regression analyses were conducted. Findings. After controlling for demographic characteristics, including age, gender, and race, respondents who reported a history of parental addictions had significantly higher odds of arthritis in comparison to individuals without $(\mathrm{OR}=1.58$; 95\% CI 1.38-1.80). Adjustment for socioeconomic status, adult health behaviors, and mental health conditions had little impact on the parental addictions and arthritis relationship. The association between parental addictions and arthritis was substantially reduced when adverse childhood experiences $(\mathrm{OR}=1.33$; $95 \%$ CI 1.15-1.53) and all four groups of risk factors collectively ( $\mathrm{OR}=1.30 ; 95 \% \mathrm{CI}=1.12-1.51$ ) were included in the analyses; however, the relationship remained statistically significant. Conclusions. A robust association was found between parental addictions and cumulative lifetime incidence of arthritis. This link remained even when controlling for four groups of potential risk factors.
\end{abstract}

\section{Introduction}

At some point in their lives, an estimated $2.6 \%$ of adult Americans have a drug disorder [1] and $15.5 \%$ have alcohol dependence [2]. The direct and indirect costs of alcohol addiction in the United States are approximately $\$ 162$ billion dollars [3]. Of this sum, $\$ 18.8$ billion is the result of health care expenditures and $\$ 6.1$ billion is due to social welfare expenditures [3]. In 2000, approximately 140000 deaths were directly related to alcohol consumption [4]. Research indicates that parents who are addicted to drugs or alcohol have lower parenting skills and higher rates of neglect [5] and physical abuse [5]. Children raised by drug addicted or alcoholic parents are vulnerable to many negative health behaviors and mental health outcomes as well as higher rates of addictions. Approximately $10 \%$ of children in the United States have at least one parent with an addiction [6].

Children of addicted parents have twice the risk of premature death in comparison to their peers who do not have addicted parents [7]. Most research has focused on the higher rates of suicide, drug and alcohol addictions, and violence as risk factors for the higher morbidity and mortality of the adolescent and adult children of alcoholic parents. Less attention has been paid to the potential longterm physical health outcomes for children raised by addicted parents. Emerging research suggests an association between household dysfunction in childhood and the later development of illness in adult years, including heart disease, stroke, cancer, diabetes, arthritis, bronchitis, or emphysema $[8,9]$. 
This paper focused on the association between parental addictions and cumulative lifetime incidence of arthritis.

Parental addictions often result in or exacerbate other adverse childhood experiences such as parental divorce [7, 10,11 , parental unemployment [12], and household poverty [12]. Children raised by parents with addictions are also at increased risk for child abuse [5,7]. Research has shown that several of these childhood risk factors, particularly childhood physical abuse [13-15], parental unemployment, and parental divorce [16] are associated with an elevated risk of osteoarthritis and/or adult onset arthritis.

A pattern of unhealthy adult behaviors is often found among individuals with a history of parental addictions. In order to deal with negative experiences, adult children of addicts may develop risky health behaviors as a coping mechanism. These behaviors may in turn lead to a person being at an increased risk for chronic diseases [8]. For example, parental addiction has been associated with adult children's alcohol abuse $[17,18]$, smoking $[17,19]$, and other substances abuse $[7,17,18]$. In turn, these health behaviors, particularly cigarette smoking $[20,21]$ and alcohol consumption [22], are associated with an elevated risk of adult onset arthritis [8].

Dysfunctional home environments, which include exposure to parental addictions, have been correlated with childhood physical inactivity [8]. In turn, inactivity leads to obesity in children which is sustained into adulthood $[17,23]$. Obesity places both men and women at an increased risk for both selfreported and radiographic knee and hip arthritis [24-29]. Patients diagnosed with arthritis by medical professionals are less likely to engage in physical activity in their leisure time compared to their peers who are not diagnosed with arthritis [30].

A negative correlation exists between parental addictions in childhood and later educational attainment $[12,31]$. With respect to adult economic status, the literature remains unclear. In a study conducted by Mathew et al. [31], there was no significant difference in socioeconomic status among children of addicts and children of nonaddicts, whereas other researchers have found that adult children of addicts are poorer with lower education attainment [32]. In turn, selfreports of arthritis have been associated with low educational attainment and low levels of income [33].

A history of parental addictions is often associated with anxiety and stress disorders in childhood [34] which may persist into adulthood [31]. In turn, anxiety and stress is associated with an elevated risk for adult onset arthritis [22]. Similarly, adults who were exposed to parental substance abuse in childhood experience higher rates of depression in adulthood [18]. Data collected from cross-sectional population-based research indicates that there is a positive correlation between depression and self-reported arthritis conditions [22] and prospective research confirms these findings [35].

Consistent findings indicate that higher rates of arthritic conditions are associated with older age $[24,25,36,37]$ and female gender $[26,37,38]$. Significant variations in the rates of arthritis conditions are also associated with race. An elevated risk of arthritis exists among First Nations, African American, and non-Hispanic white populations, whereas
Hispanic and Chinese individuals have lower rates of arthritis [37, 39-41].

Based on a large, regionally representative Canadian sample, this study investigated the relationship between selfreports of childhood exposures to parental alcohol or drug addictions and self-reports of health professionals' diagnosis of arthritis. In order to study this relationship, adjustments were made for age, gender, and race, in addition to the following four types of risk factors: (1) adult socioeconomic status; (2) adult health behaviors; (3) other adverse childhood experiences; and (4) mood and anxiety disorders.

\section{Materials and Methods}

Statistics Canada's 2005 Canadian Community Health Survey (CCHS 3.1) was a nationally representative, multistage stratified survey of health status, health care usage, and determinants of health [42]. Respondents from the provinces of Manitoba and Saskatchewan included 13,074 adults with complete data on arthritis status, of whom 13,036 also had complete data on childhood experience of parental addictions. These provinces were the only two in the survey that asked questions about adverse childhood experiences and parental addictions. The provincial response rate for Manitoba was $83.3 \%$ and the response rate in Saskatchewan was $84.1 \%$ [42].

2.1. Statistical Analyses. Logistic regression analyses were conducted to investigate the association between parental addictions and arthritis. The initial analysis and each subsequent analysis included parental addictions, race, gender, and age. The second analysis examined adult socioeconomic status including level of educational achievement and household income. The third analysis examined health risk behaviors in adulthood including smoking, alcohol consumption, activity level, and obesity. The fourth model included other adverse childhood experiences including parental divorce/separation, childhood abuse, and parental unemployment/childhood poverty. The fifth analysis focused on adult mental health including mood and anxiety disorders. The final model controlled for all of the aforementioned factors. The purpose of the analysis was to examine the impact that controlling for additional risk factors would have on the association between parental addictions and arthritis.

In the logistic regression analyses, the sample size varied from $n=12,893$ in the age-sex-race adjusted model $(1.4 \%$ missing) to $n=12,460$ in the fully adjusted model $(4.7 \%$ missing). All prevalence data, odds ratios, and confidence intervals reported are weighted to adjust for the probability of selection and nonresponse. Sample sizes are always reported in their unweighted form.

\subsection{Measures}

2.2.1. History of Parental Addictions. The survey asked respondents to report on their experiences while living at home in their childhood and teenage years. Exposure to parental addictions was determined through a positive 
response to the following question: "did either of your parents drink or use drugs so often that it caused problems for the family?"

2.2.2. Arthritis. Respondents were asked to report on their experiences with chronic illnesses that were "long-term conditions that have lasted or are expected to last six months or more" and that "had been diagnosed by a health professional." Individuals were then asked if they had "Arthritis or rheumatism, excluding fibromyalgia?"

2.2.3. Demographic Characteristics. Demographic characteristics that were included in the analyses were age (18-39, then by decade until 79, then 80 and older) and self-reported race (visible minority and white).

2.2.4. Adverse Childhood Experiences. Using the same preamble as the parental addictions questions described above, other adverse childhood experiences were determined based on responses to questions regarding parental unemployment ("Did your father or mother not have a job for a long time when they wanted to be working?") childhood physical abuse ("Were you ever physically abused by someone close to you?"), and parental divorce ("Did your parents get a divorce?").

2.2.5. Adult Health Behaviors. Adult health behaviors included in the analysis comprised smoking status, body mass index (BMI), activity level, and level of alcohol consumption. Self-reported smoking status was categorized as either current or former smokers compared to never smokers. Body Mass Index was based on self-reported data on weight and height, which was then placed into four categories: obese $(\mathrm{BMI}=30$ or above), overweight $(\mathrm{BMI}=$ 25-29.99), normal (BMI < 25), and a category for missing data. Activity level was based on energy expenditure in kilocalories per kilogram per day in leisure time recreational activity (inactive $<1.5 \mathrm{kcal}$; moderately active $1.5-2.9 \mathrm{kcal}$; active $3.0 \mathrm{kcal}$ or greater). A measure of alcohol consumption was based on self-reports of average daily intake according to abstainer/very light drinker (nondrinker or average of 0 alcohol intake per day), low consumption (women: one drink per day; men: two drinks per day), and hazardous/harmful consumption (women: two or more drinks per day; men: three or more drinks per day).

2.2.6. Adult Socioeconomic Status. Adult socioeconomic status included level of education (less than high school, high school graduation, and postsecondary graduation) and household income $(<\$ 15,000, \$ 15,000-\$ 29,999, \$ 30,000-$ $\$ 49,999, \$ 50,000$ or more, missing).

2.2.7. Mental Health: Mood and Anxiety Disorders. Respondents were asked if they had the following "long-term conditions that have lasted or are expected to last six months or more and that had been diagnosed by a health professional": "do you have a mood disorder such as depression, bipolar disorder, mania, or dysthymia?" Anxiety disorders were assessed using the question "Do you have an anxiety disorder such as a phobia, obsessive compulsive disorder, or a panic disorder?"

It should be noted that it is impossible to determine with this dataset the timing of the onset of the adult health behaviors and mental health problems. They may have begun before or after the onset of arthritis.

\section{Results and Discussion}

One in five respondents in the regional representative sample used for this study, reported they had been diagnosed by a health professional with arthritis $(20.4 \%$; $95 \%$ CI $=$ $18.9 \%-21.9 \%)$. The prevalence of self-reported experiences of parental addictions was found to be $14.5 \%$ (95\% CI $=13.1 \%-$ 15.9\%). Sample characteristics are presented in Table 1.

After controlling for age, gender, and race, individuals with a history of parental addictions had a significantly higher odds of self-reporting arthritis, as compared to their peers who did not report a history of parental addictions $(\mathrm{OR}=$ $1.58,95 \%$ CI 1.38-1.80), as shown in Table 2.

Further adjustment of three categories of potential risk factors failed to make significant impact on the strength of the relationship between history of parental addictions and arthritis: adult socioeconomic status (OR $=1.56,95 \% \mathrm{CI}$ 1.37-1.79), adult health behaviors (OR $=1.54,95 \%$ CI $1.35-$ 1.76), mood disorders, and anxiety disorders ( $\mathrm{OR}=1.49,95 \%$ CI 1.30-1.70). Adjusting for other adverse childhood experiences had the greatest impact on the association between arthritis and a history of parental addictions ( $\mathrm{OR}=1.33,95 \%$ CI 1.15-1.53). The parental addictions-arthritis relationship remained significant after controlling for all four clusters of potential risk factors (OR $=1.3095 \%$ CI 1.12-1.51).

This study indicated that the prevalence in Manitoba and Saskatchewan of arthritis is $20.4 \%$. This is a little higher than estimates of the national prevalence rate of $15.3 \%$ [43]. One in seven respondents reported that at least one of their parents drank or used drugs so often that it caused problems for the family. National data from the United States suggest approximately one in every ten children currently have at least one parent with a substance dependency problem [6].

In this study, respondents who reported a history of parental addictions had significantly higher odds of arthritis. The association between parental substance abuse and arthritis remained significant even after controlling for demographic characteristics and four additional groups of factors that are strongly associated with parental addictions, namely, other adverse childhood experiences, adult health behaviors, adulthood socioeconomic position, and mental health issues (i.e., mood disorders and anxiety disorders).

These findings support previous research demonstrating an increased risk of arthritis in adults who were raised by parents with substance abuse problems [44]. Von Korff and colleagues [44] found odds ratios of $1.38(95 \% \mathrm{CI}=1.14,1.67)$ for adult onset arthritis among adults reporting a history of parental substance abuse. These odds ratios are comparable to our findings for arthritis and parental addictions (OR = 1.30, 95\% CI 1.12-1.51) in the final model. Von Korff et al. 
TABLE 1: Description of those with arthritis and those without arthritis*.

\begin{tabular}{|c|c|c|c|}
\hline & $\begin{array}{c}\text { No arthritis } \\
(n=9656)\end{array}$ & $\begin{array}{c}\text { Arthritis } \\
(n=3418)\end{array}$ & $\begin{array}{c}\text { Total } \\
(n=13074)\end{array}$ \\
\hline \multicolumn{4}{|l|}{ Key variable of interest } \\
\hline \multicolumn{4}{|l|}{ Parental addiction } \\
\hline No & $8,245(85.9 \%)$ & $2,937(83.9 \%)$ & $11,182(85.5 \%)$ \\
\hline Yes & $1,386(14.1 \%)$ & $468(16.1 \%)$ & $1,854(14.5 \%)$ \\
\hline \multicolumn{4}{|l|}{ Control variables } \\
\hline \multicolumn{4}{|l|}{ Sex } \\
\hline Male & $4,540(50.6 \%)$ & $1,203(40.1 \%)$ & $5,743(48.4 \%)$ \\
\hline Female & $5,116(49.4 \%)$ & $2,215(59.9 \%)$ & $7,331(51.6 \%)$ \\
\hline \multicolumn{4}{|l|}{ Age, years } \\
\hline $12-39$ & $4,069(46.9 \%)$ & $227(8.7 \%)$ & $4,296(39.1 \%)$ \\
\hline $40-49$ & $1,725(22.0 \%)$ & $326(15.2 \%)$ & $2,051(20.6 \%)$ \\
\hline $50-59$ & $1,525(15.6 \%)$ & $709(24.1 \%)$ & $2,234(17.3 \%)$ \\
\hline $60-69$ & $1,054(7.9 \%)$ & $764(20.5 \%)$ & $1,818(10.4 \%)$ \\
\hline $70-79$ & $777(5.1 \%)$ & $819(19.3 \%)$ & $1,596(8.0 \%)$ \\
\hline$\geq 80$ & $506(2.5 \%)$ & $574(12.2 \%)$ & $1,079(4.5 \%)$ \\
\hline \multicolumn{4}{|l|}{ Race } \\
\hline White & $8,340(85.1 \%)$ & $3,119(91.3 \%)$ & $11,459(86.4 \%)$ \\
\hline Visible minority & $1,210(14.9 \%)$ & $260(8.7 \%)$ & $1,470(13.6 \%)$ \\
\hline \multicolumn{4}{|l|}{ Adult Socioeconomic Status } \\
\hline \multicolumn{4}{|l|}{ Education } \\
\hline Less than high school & $2,074(16.1 \%)$ & $1,362(32.8 \%)$ & $3,436(19.5 \%)$ \\
\hline High school graduate & $2,750(31.1 \%)$ & $688(24.0 \%)$ & $3,438(29.7 \%)$ \\
\hline Postsecondary graduate & $4,729(52.8 \%)$ & $1,324(43.2 \%)$ & $6,053(50.8 \%)$ \\
\hline \multicolumn{4}{|l|}{ Household income } \\
\hline Missing data & $1,328(13.5 \%)$ & $547(15.4 \%)$ & $1,875(13.9 \%)$ \\
\hline$<\$ 15,000$ & $804(4.7 \%)$ & $527(10.8 \%)$ & $1,331(6.0 \%)$ \\
\hline$\$ 15,000-\$ 29,999$ & $1,434(10.2 \%)$ & $822(18.8 \%)$ & $2,256(12.0 \%)$ \\
\hline$\$ 30,000-\$ 49,999$ & $1,929(18.5 \%)$ & $684(20.9 \%)$ & $2,613(19.0 \%)$ \\
\hline$\geq \$ 50,000$ & $4,161(53.1 \%)$ & $838(34.1 \%)$ & $4,999(49.3 \%)$ \\
\hline \multicolumn{4}{|l|}{ Adult health behaviours } \\
\hline \multicolumn{4}{|l|}{ Body Mass Index category, } \\
\hline Underweight or normal & $4,135(45.3 \%)$ & $1,093(32.5 \%)$ & $5,228(42.7 \%)$ \\
\hline Overweight & $3,323(34.6 \%)$ & $1,242(37.4 \%)$ & $4,565(35.2 \%)$ \\
\hline Obese & $1,809(16.8 \%)$ & $972(27.5 \%)$ & 2,781 (19.0\%) \\
\hline Missing data & $389(3.3 \%)$ & $111(2.5 \%)^{\mathrm{E}}$ & $500(3.2 \%)$ \\
\hline \multicolumn{4}{|l|}{ Smoking status } \\
\hline Current or former & $6,532(65.3 \%)$ & $2,381(72.5 \%)$ & $8,913(66.7 \%)$ \\
\hline Never & $3,114(34.7 \%)$ & $1,034(27.5 \%)$ & $4,148(33.3 \%)$ \\
\hline \multicolumn{4}{|l|}{ Alcohol use } \\
\hline Abstainer/very light drinker & $6,874(69.8 \%)$ & $2,789(79.8 \%)$ & $9,663(71.8 \%)$ \\
\hline Lower consumption & $2,099(24.8 \%)$ & $472(17.9 \%)$ & $2,571(23.4 \%)$ \\
\hline Higher consumption & $508(5.4 \%)$ & $92(2.4 \%)^{\mathrm{E}}$ & $600(4.8 \%)$ \\
\hline \multicolumn{4}{|l|}{ Physical activity level } \\
\hline Active & $2,317(24.1 \%)$ & $573(16.6 \%)$ & $2,890(22.5 \%)$ \\
\hline Moderate & $2,380(25.2 \%)$ & $737(22.2 \%)$ & $3,117(24.6 \%)$ \\
\hline Inactive & $4,949(50.8 \%)$ & $2,100(61.3 \%)$ & $7,049(52.9 \%)$ \\
\hline
\end{tabular}


TABle 1: Continued.

\begin{tabular}{|c|c|c|c|}
\hline & $\begin{array}{c}\text { No arthritis } \\
(n=9656)\end{array}$ & $\begin{array}{c}\text { Arthritis } \\
(n=3418)\end{array}$ & $\begin{array}{c}\text { Total } \\
(n=13074)\end{array}$ \\
\hline \multicolumn{4}{|c|}{ Childhood stressors } \\
\hline \multicolumn{4}{|c|}{ Physically abused as a child } \\
\hline No & $8,951(93.5 \%)$ & $3,100(89.3 \%)$ & $12,051(92.6 \%)$ \\
\hline Yes & $705(6.5 \%)$ & $318(10.7 \%)$ & $1,023(7.3 \%)$ \\
\hline \multicolumn{4}{|c|}{ Parents unemployed for a long time } \\
\hline No & $8,743(90.9 \%)$ & $3,068(90.6 \%)$ & $11,829(90.8 \%)$ \\
\hline Yes & $816(9.1 \%)$ & $280(9.4 \%)$ & $1,096(9.2 \%)$ \\
\hline \multicolumn{4}{|c|}{ Parents divorced } \\
\hline No & $8,524(86.9 \%)$ & $3,133(91.2 \%)$ & $11,695(87.8 \%)$ \\
\hline Yes & $1,121(13.1 \%)$ & $239(8.8 \%)$ & $1,360(12.2 \%)$ \\
\hline \multicolumn{4}{|c|}{ Mental health } \\
\hline \multicolumn{4}{|c|}{ Has mood disorder } \\
\hline No & $9,158(95.0 \%)$ & $2,434(91.5 \%)$ & $12,291(94.3 \%)$ \\
\hline Yes & $493(5.0 \%)$ & $283(8.5 \%)$ & $776(5.7 \%)$ \\
\hline \multicolumn{4}{|c|}{ Has anxiety disorder } \\
\hline No & $9,283(96.2 \%)$ & $3,208(92.9 \%)$ & $12,491(95.6 \%)$ \\
\hline Yes & $367(3.6 \%)$ & $206(7.1 \%)$ & $573(4.4 \%)$ \\
\hline
\end{tabular}

${ }^{*}$ Values are the unweighted number (weighted percentages). Source: Canadian Community Health Survey 2005.

${ }^{\mathrm{E}}$ Indicates that estimate is associated with a moderately high sampling variability and therefore should be interpreted with caution.

controlled for two of the factors that were controlled for in this study including gender and current age of respondent [44]. However, our study controlled for several additional risk factors not included in the Von Korff and colleagues study [44]. These variables included adult obesity, physical activity level, and smoking. Of these variables, adult obesity, and physical inactivity are most clearly associated with arthritis [24-29].

Kopec and Sayre's Canadian cohort study [45] used fouryear prospective data of respondents who were free of arthritis at baseline. They found an elevated but nonsignificant risk of arthritis (hazard risk ratio $=1.22,95 \% \mathrm{CI}=0.91,1.62$ ) among those who reported a history of parental addictions. Their use of a longitudinal design and the inclusion of a wide range of potentially confounding variables make Kopec and Sayre's findings particularly important. As in this study, Kopec and Sayre used a Canadian sample as well as any self-reported arthritic condition as the outcome measure. Although the odds of arthritis among those who had experienced parental addictions were comparable to Kopec and Sayre's in our fully adjusted model (1.30, 95\% CI 1.13-1.53), our odds ratios reached statistical significance while Kopec and Sayre's did not. Our sample was much larger than Kopec and Sayre's and therefore had greater power to detect a statistical difference. This greater statistical power was due to the crosssectional nature of our research that allowed us to examine the parental addictions-arthritis relationship with cumulative lifetime incidence that included both child-onset and adultonset arthritis. In contrast, Kopec and Sayre were restricted in their prospective study of those aged 18 and over to the 1006 new cases of arthritis that emerged during the four-year course of their study, which were all adult-onset cases. Future prospective studies would benefit from larger samples and longer follow-up periods.

The seminal researchers in the field have suggested that adult health behaviors largely account for the relationship between exposure to parental addictions and adult health conditions (i.e., [46]). However, when our analyses were adjusted for health behaviors, including smoking, alcohol consumption, physical activity level, and obesity, the addictions-arthritis link did not change substantially $(\mathrm{OR}=$ $1.54,95 \% \mathrm{CI}=1.35-1.76)$ in comparison to the base model $(\mathrm{OR}=1.58,95 \% \mathrm{CI}=1.38-1.80)$.

Adjusting for other adverse childhood experiences reduced the magnitude of the association between exposure to parental substance abuse and arthritis $(\mathrm{OR}=1.33,95 \% \mathrm{CI}$ $=1.15,1.53)$ more substantially than any of the other cluster of risk factors. As was noted above, parental addictions often contribute to negative childhood experiences such as childhood abuse, parental unemployment, poverty, and parental divorce. Previous research has found that there is a strong correlation between a history of parental addictions and experiences of child abuse [5, 47, 48]. It is important to note, however, that the parental addictions-arthritis association remained statistically significant even when adjustments were made for these childhood stressors and a wide range of other risk factors.

An important avenue for future research is the "biological embedding" of adverse childhood experiences [49, 50]. The hypothalamus-pituitary-adrenal axis (HPA) may play a role in the later development of chronic disease in adulthood. Chronic stress in childhood, which can be induced by 


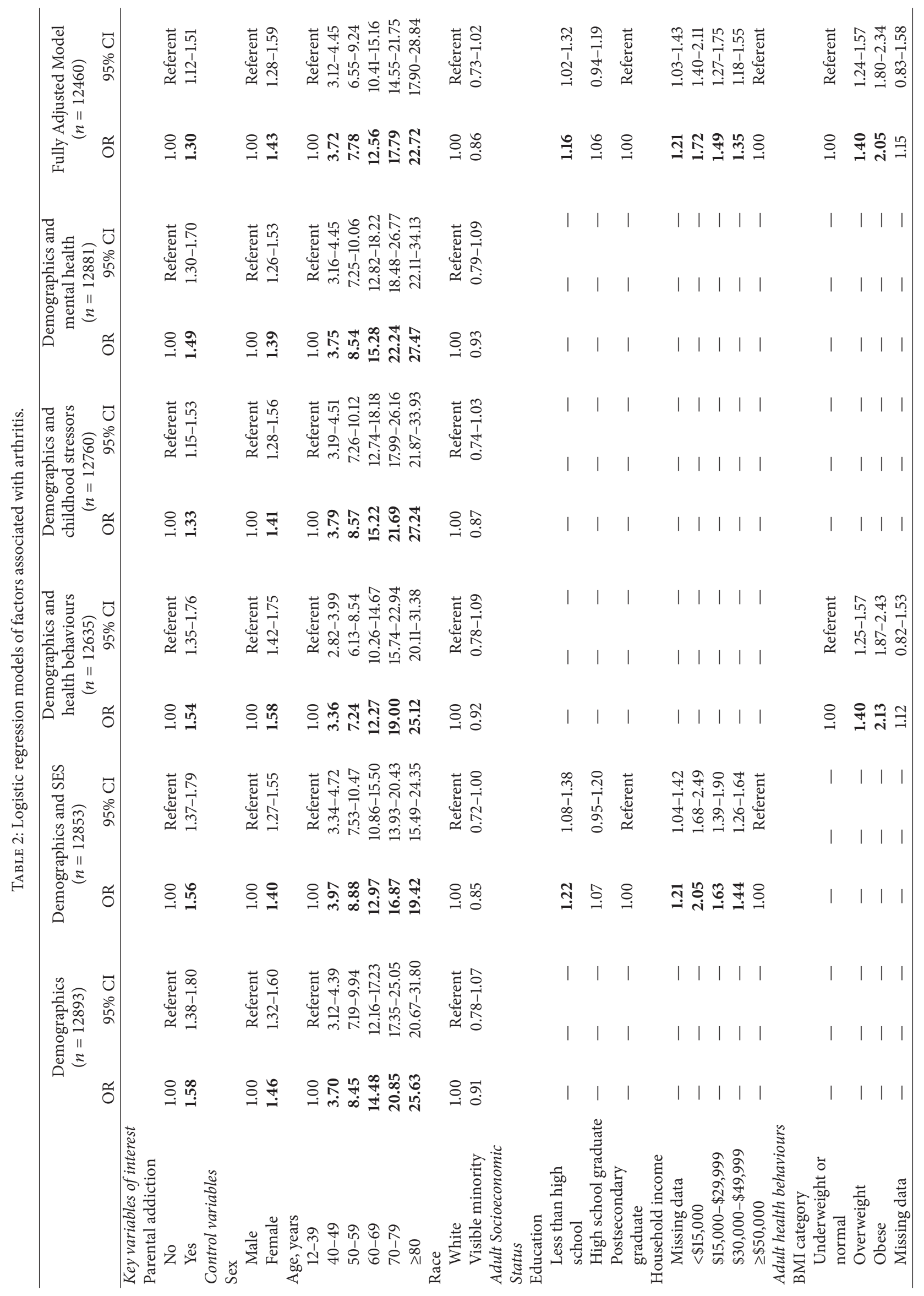




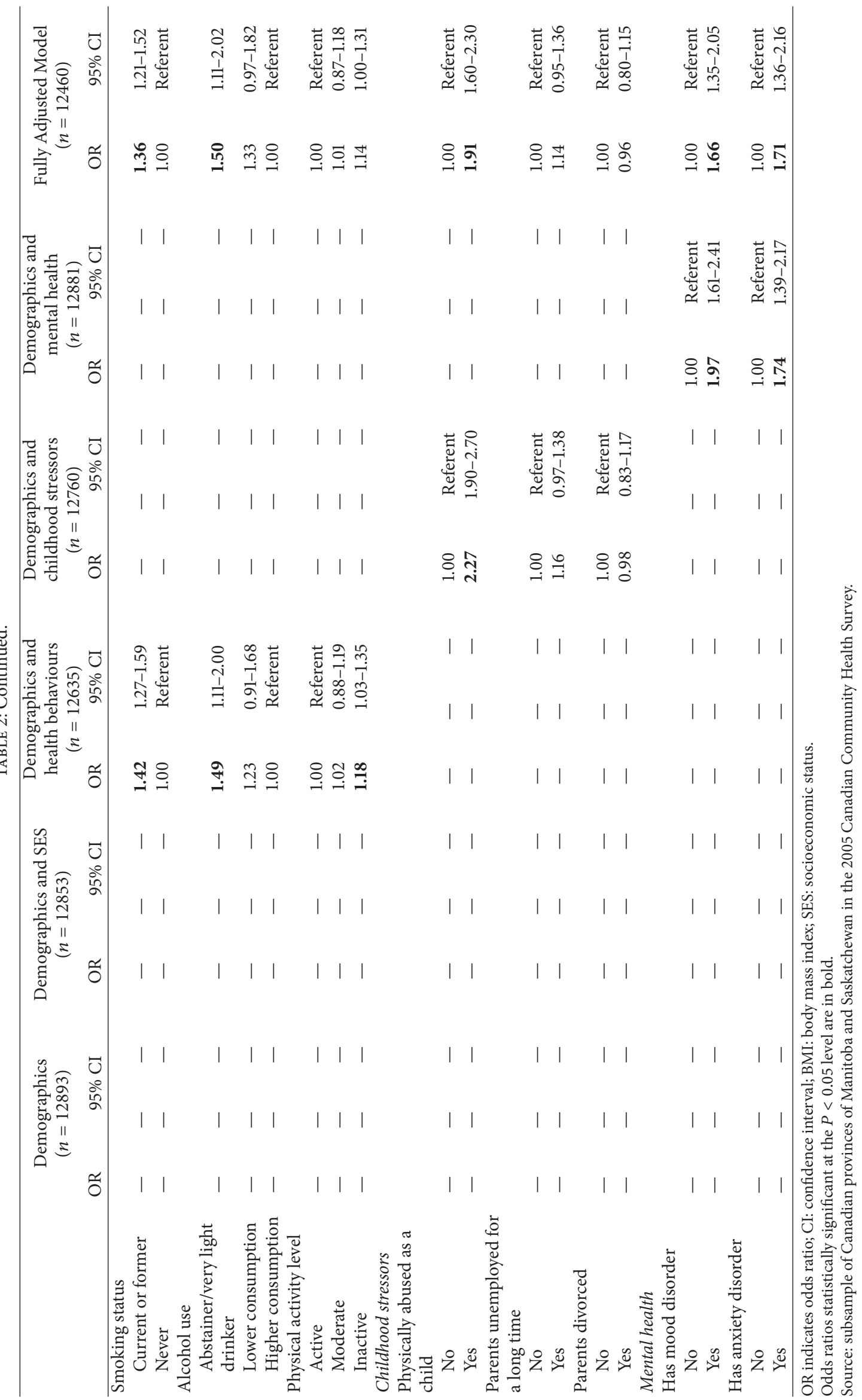


parental addictions, may create long-term dysfunctions in the HPA axis that could result in problematic responses to future stressors $[49,51]$. Abnormal HPA axis functioning has been associated with arthritic symptoms [52].

There are several limitations to this study. We had to rely on self-report of a health professional's diagnosis of arthritis and self-report of parental addictions. Although reasonable concordance (87\% [53] to 81\% [54]) has been found between self-report of arthritis and a physician's diagnosis, future research would benefit from the use of medical examinations or chart reviews. Previous researchers have indicated that adult children of alcoholics are able to provide reliable and valid reports of parental addictions $[55,56]$.

Furthermore, the CCHS did not ask questions on several important factors including gender of the parent with an addiction and the severity and form of addiction (drug, alcohol, etc.). The gender of the addicted parent mediates the experience of adult related health outcomes [7, 12, 57]. There were several other potential mediating risk factors for arthritis that were not controlled for in this analysis due to limitations in the CCHS dataset. Risk factors that may have confounded with the results include joint vulnerability $[24,26,58,59]$, bone mineral density [24], estrogen deficiency [24], and genetic factors [24, 60, 61]. Unfortunately, we could not determine in the CCHS whether the adult health behaviors and mental health problems had begun prior to or after the onset of arthritis. Future research would benefit from longitudinal data collection to untangle these associations.

The strengths of this study include the use of a large, regionally representative sample to examine the relationship between of parental addictions and arthritis. With a response rate of $84 \%$, the quality of the data used in this study was high. Finally, the dataset provided responses to a broad range of questions allowing us to control for more factors than most previous research studies.

Future research would benefit from a focus on factors associated with resilience. Reich et al. [10] found that children of alcoholics who reported positive relationships with their parents were in turn significantly less disturbed than children of alcoholics who did not experience positive relationships with their parents. Thus, future research should explore parent-child relationships and resiliency in order to design interventions that may assist in promoting better outcomes.

\section{Conclusions}

To conclude, despite controlling for a broad range of potentially mediating risk factors, the relationship between experiencing a history of parental addictions and the cumulative lifetime incidence of arthritis in adulthood was strong. Future research would benefit from a prospective research design, which would assist investigators to identify the potential pathways that mediate the relationship between parental addictions and a diagnosis of arthritis in adulthood. Future studies should examine psychophysiological factors, such as HPA axis dysfunction, that may provide useful insights.

\section{Conflict of Interests}

The authors declare that there is no conflict of interests regarding the publication of this paper.

\section{Acknowledgments}

The authors would like to thank Araf Khaled, Yi Xin Rachel Zhou and Marla Battiston for assistance with preparation of the tables. The first author (Esme Fuller-Thomson) would like to gratefully acknowledge support received from the Sandra Rotman Endowed Chair in Social Work.

\section{References}

[1] W. M. Compton, Y. F. Thomas, K. P. Conway, and J. D. Colliver, "Developments in the epidemiology of drug use and drug use disorders," The American Journal of Psychiatry, vol. 162, no. 8, pp. 1494-1502, 2005.

[2] R. A. Grucza, K. K. Bucholz, J. P. Rice, and L. J. Bierut, "Secular trends in the lifetime prevalence of alcohol dependence in the United States: a re-evaluation," Alcoholism, vol. 32, no. 5, pp. 763-770, 2008.

[3] H. J. Harwood, D. Fountain, and G. Livermore, "Economic costs of alcohol abuse and alcoholism," in Recent Developments in Alcoholism, vol. 14, pp. 307-330, 1998.

[4] A. H. Mokdad, J. S. Marks, D. F. Stroup, and J. L. Gerberding, "Actual causes of death in the United States, 2000," The Journal of the American Medical Association, vol. 291, no. 10, pp. 12381245, 2004.

[5] R. Famularo, R. Kinscherff, and T. Fenton, "Parental substance abuse and the nature of child maltreatment," Child Abuse \& Neglect, vol. 16, no. 4, pp. 475-483, 1992.

[6] N. A. Conners, P. Bokony, L. Whiteside-Mansell, R. H. Bradley, and J. Liu, "Addressing the treatment needs of children affected by maternal addiction: challenges and solutions," Evaluation and Program Planning, vol. 27, no. 2, pp. 241-247, 2004.

[7] M. N. Christoffersen and K. Soothill, "The long-term consequences of parental alcohol abuse: a cohort study of children in Denmark," Journal of Substance Abuse Treatment, vol. 25, no. 2, pp. 107-116, 2003.

[8] V. J. Felitti, R. F. Anda, D. Nordenberg et al., "Relationship of childhood abuse and household dysfunction to many of the leading causes of death in adults: the adverse childhood experiences (ACE) study," American Journal of Preventive Medicine, vol. 14, no. 4, pp. 245-258, 1998.

[9] M. R. von Korff, K. M. Scott, and O. Gureje, Eds., Global Perspectives on Mental-Physical Comorbidity in the WHO World Mental Health Surveys, Cambridge University Press, Cambridge, UK.

[10] W. Reich, F. Earls, and J. Powell, "A comparison of the home and social environments of children of alcoholic and non-alcoholic parents," British Journal of Addiction, vol. 83, no. 7, pp. 831-839, 1988.

[11] R. F. Anda, C. L. Whitfield, V. J. Felitti et al., "Adverse childhood experiences, alcoholic parents, and later risk of alcoholism and depression," Psychiatric Services, vol. 53, no. 8, pp. 1001-1009, 2002.

[12] L. A. Bennett, S. J. Wolin, and D. Reiss, "Cognitive, behavioral, and emotional problems among school-age children of alcoholic parents," The American Journal of Psychiatry, vol. 145, no. 2, pp. 185-190, 1988. 
[13] R. D. Goodwin and M. B. Stein, "Association between childhood trauma and physical disorders among adults in the United States," Psychological Medicine, vol. 34, no. 3, pp. 509-520, 2004.

[14] E. Fuller-Thomson, M. Stefanyk, and S. Brennenstuhl, "The robust association between childhood physical abuse and osteoarthritis in adulthood: findings from a population based study," Arthritis Care \& Research, vol. 61, no. 11, pp. 1554-1562, 2009.

[15] K. W. Springer, J. Sheridan, D. Kuo, and M. Carnes, "Long-term physical and mental health consequences of childhood physical abuse: results from a large population-based sample of men and women," Child Abuse \& Neglect, vol. 31, no. 5, pp. 517-530, 2007.

[16] J. A. Kopec and E. C. Sayre, "Traumatic experiences in childhood and the risk of arthritis: a prospective cohort study," Canadian Journal of Public Health, vol. 95, no. 5, pp. 361-365, 2004.

[17] R. F. Anda, V. J. Felitti, J. D. Bremner et al., "The enduring effects of abuse and related adverse experiences in childhood," European Archives of Psychiatry and Clinical Neuroscience, vol. 256, no. 3, pp. 174-186, 2006.

[18] L. Chassin, S. C. Pitts, C. DeLucia, and M. Todd, "A longitudinal study of children of alcoholics: predicting young adult substance use disorders, anxiety, and depression," Journal of Abnormal Psychology, vol. 108, no. 1, pp. 106-119, 1999.

[19] R. Velleman and J. Orford, "The adult adjustment of offspring of parents with drinking problems," The British Journal of Psychiatry, vol. 162, pp. 503-516, 1993.

[20] A. Samanta, A. Jones, M. Regan, T. S. Wilson, and M. Doherty, "Is osteoarthritis in women affected by hormonal changes or smoking?” Rheumatology, vol. 32, no. 5, pp. 366-370, 1993.

[21] D. Hutchinson, L. Shepstone, R. Moots, J. T. Lear, and M. P. Lynch, "Heavy cigarette smoking is strongly associated with rheumatoid arthritis (RA), particularly in patients without a family history of RA," Annals of the Rheumatic Diseases, vol. 60, no. 3, pp. 223-227, 2001.

[22] Y. He, M. Zhang, E. H. B. Lin et al., "Mental disorders among persons with arthritis: results from the World Mental Health Surveys," Psychological Medicine, vol. 38, no. 11, pp. 1639-1650, 2008.

[23] V. J. Felitti, "Childhood sexual abuse, depression, and family dysfunction in adult obese patients: a case control study," Southern Medical Journal, vol. 86, no. 7, pp. 732-736, 1993.

[24] L. Sharma, D. Kapoor, and S. Issa, "Epidemiology of osteoarthritis: an update," Current Opinion in Rheumatology, vol. 18, no. 2, pp. 147-156, 2006.

[25] D. J. Hart, D. V. Doyle, and T. D. Spector, "Incidence and risk factors for radiographic knee osteoarthritis in middle-aged women: the Chingford study," Arthritis \& Rheumatism, vol. 42, no. 1, pp. 17-24, 1999.

[26] C. Cooper, H. Inskip, P. Croft et al., "Individual risk factors for hip osteoarthritis: obesity, hip injury, and physical activity," American Journal of Epidemiology, vol. 147, no. 6, pp. 516-522, 1998.

[27] C. Szoeke, L. Dennerstein, J. Guthrie, M. Clark, and F. Cicuttini, "The relationship between prospectively assessed body weight and physical activity and prevalence of radiological knee osteoarthritis in postmenopausal women," The Journal of Rheumatology, vol. 33, no. 9, pp. 1835-1840, 2006.

[28] B. Järvholm, S. Lewold, H. Malchau, and E. Vingård, "Age, bodyweight, smoking habits and the risk of severe osteoarthritis in the hip and knee in men," European Journal of Epidemiology, vol. 20 , no. 6 , pp. 537-542, 2005.
[29] A. M. Lievense, S. M. A. Bierma-Zeinstra, A. P. Verhagen, M. E. van Baar, J. A. N. Verhaar, and B. W. Koes, "Influence of obesity on the development of osteoarthritis of the hip: a systematic review," Rheumatology, vol. 41, no. 10, pp. 1155-1162, 2002.

[30] M. Shih, J. M. Hootman, J. Kruger, and C. G. Helmick, "Physical activity in men and women with arthritis: National Health Interview Survey, 2002," American Journal of Preventive Medicine, vol. 30, no. 5, pp. 385-393, 2006.

[31] R. J. Mathew, W. H. Wilson, D. G. Blazer, and L. K. George, "Psychiatric disorders in adult children of alcoholics: data from the epidemiologic catchment area project," The American Journal of Psychiatry, vol. 150, no. 5, pp. 793-800, 1993.

[32] E. M. Hill, L. T. Ross, S. A. Mudd, and F. C. Blow, "Adulthood functioning: the joint effects of parental alcoholism, gender and childhood socio-economic stress," Addiction, vol. 92, no. 5, pp. 583-596, 1997.

[33] M. Cañizares, J. D. Power, A. V. Perruccio, and E. M. Badley, "Association of regional racial/cultural context and socioeconomic status with arthritis in the population: a multilevel analysis," Arthritis Care \& Research, vol. 59, no. 3, pp. 399-407, 2008.

[34] T. E. Wilens, J. Biederman, E. B. Licsw et al., "A family study of the high-risk children of opioid- and alcohol-dependent parents," The American Journal on Addictions, vol. 11, no. 1, pp. $41-51,2002$.

[35] W. G. Seavey, J. H. Kurata, and R. D. Cohen, "Risk factors for incident self-reported arthritis in a 20 year followup of the Alameda county study cohort," The Journal of Rheumatology, vol. 30, no. 10, pp. 2103-2111, 2003.

[36] C. E. I. Szoeke, F. M. Cicuttini, J. R. Guthrie, M. S. Clark, and L. Dennerstein, "Factors affecting the prevalence of osteoarthritis in healthy middle-aged women: data from the longitudinal Melbourne Women's Midlife Health Project," Bone, vol. 39, no. 5, pp. 1149-1155, 2006.

[37] R. C. Lawrence, D. T. Felson, C. G. Helmick et al., "Estimates of the prevalence of arthritis and other rheumatic conditions in the United States: part II," Arthritis \& Rheumatism, vol. 58, no. 1, pp. 26-35, 2008.

[38] V. K. Srikanth, J. L. Fryer, G. Zhai, T. M. Winzenberg, D. Hosmer, and G. Jones, "A meta-analysis of sex differences prevalence, incidence and severity of osteoarthritis," Osteoarthritis and Cartilage, vol. 13, no. 9, pp. 769-781, 2005.

[39] M. Cañizares, J. D. Power, A. V. Perruccio, and E. M. Badley, "Association of regional racial/cultural context and socioeconomic status with arthritis in the population: a multilevel analysis," Arthritis Care \& Research, vol. 59, no. 3, pp. 399-407, 2008.

[40] M. C. Nevitt, L. Xu, Y. Zhang et al., "Very low prevalence of hip osteoarthritis among Chinese elderly in Beijing, China, compared with whites in the United States: the Beijing osteoarthritis study," Arthritis \& Rheumatism, vol. 46, no. 7, pp. 1773-1779, 2002.

[41] C. G. Helmick, D. T. Felson, R. C. Lawrence et al., "Estimates of the prevalence of arthritis and other rheumatic conditions in the United States: part I," Arthritis \& Rheumatism, vol. 58, no. 1, pp. 15-25, 2008.

[42] Statistics Canada (2006), Canadian Community Health Survey (CCHS), Cycle 3.1 (2005), Public Use Microdata File (PUMF) User guide, 2010.

[43] Health Canada (2003), "Arthritis in Canada: an ongoing challenge," 2010. 
[44] M. von Korff, J. Alonso, J. Ormel et al., "Childhood psychosocial stressors and adult onset arthritis: broad spectrum risk factors and allostatic load," Pain, vol. 143, no. 1-2, pp. 76-83, 2009.

[45] J. A. Kopec and E. C. Sayre, "Traumatic experiences in childhood and the risk of arthritis: a prospective cohort study," Canadian Journal of Public Health, vol. 95, no. 5, pp. 361-365, 2004.

[46] V. J. Felitti, R. F. Anda, D. Nordenberg et al., "Relationship of childhood abuse and household dysfunction to many of the leading causes of death in adults: the adverse childhood experiences (ACE) study," American Journal of Preventive Medicine, vol. 14, no. 4, pp. 245-258, 1998.

[47] K. Kelleher, M. Chaffin, J. Hollenberg, and E. Fischer, "Alcohol and drug disorders among physically abusive and neglectful parents in a community-based sample," American Journal of Public Health, vol. 84, no. 10, pp. 1586-1590, 1994.

[48] E. Fuller-Thomson, M. Stefanyk, and S. Brennenstuhl, "The robust association between childhood physical abuse and osteoarthritis in adulthood: findings from a representative community sample," Arthritis Care \& Research, vol. 61, no. 11, pp. 1554-1562, 2009.

[49] C. Hertzman, "The biological embedding of early experience and its effects on health in adulthood," Annals of the New York Academy of Sciences, vol. 896, pp. 85-95, 1999.

[50] C. Power and C. Hertzmant, "Social and biological pathways linking early life and adult disease," British Medical Bulletin, vol. 53, no. 1, pp. 210-221, 1997.

[51] D. L. Tosevski and M. P. Milovancevic, "Stressful life events and physical health," Current Opinion in Psychiatry, vol. 19, no. 2, pp. 184-189, 2006.

[52] C. W. Denko and C. J. Malemud, "Role of the growth hormone/ insulin-like growth factor-1 paracrine axis in rheumatic diseases," Seminars in Arthritis \& Rheumatism, vol. 35, no. 1, pp. 24-34, 2005.

[53] J. H. Barlow, A. P. Turner, and C. C. Wright, "Comparison of clinical and self-reported diagnoses for participants on a community-based arthritis self-management programme," British Journal of Rheumatology, vol. 37, no. 9, pp. 985-987, 1998.

[54] L. M. March, J. M. Schwarz, B. H. Carfrae, and E. Bagge, "Clinical validation of self-reported osteoarthritis," Osteoarthritis and Cartilage, vol. 6, no. 2, pp. 87-93, 1998.

[55] W. H. George, J. La Marr, K. Barrett, and T. McKinnon, "Alcoholic parentage, self-labeling, and endorsement of ACOAcodependent traits," Psychology of Addictive Behaviors, vol. 13, no. 1, pp. 39-48, 1999.

[56] D. S. Cowley and C. Godon, "Assessment of family history of alcoholism in sons of alcoholic fathers," Journal of Addictive Diseases, vol. 14, no. 2, pp. 75-81, 1995.

[57] R. E. Drake and G. E. Vaillant, "Predicting alcoholism and personality disorder in a 33-year longitudinal study of children of alcoholics," British Journal of Addiction, vol. 83, no. 7, pp. 799807, 1988.

[58] A. J. Sutton, K. R. Muir, S. Mockett, and P. Fentem, "A casecontrol study to investigate the relation between low and moderate levels of physical activity and osteoarthritis of the knee using data collected as part of the Allied Dunbar National Fitness Survey," Annals of the Rheumatic Diseases, vol. 60, no. 8, pp. 756-764, 2001.

[59] D. Coggon, S. Kellingray, H. Inskip, P. Croft, L. Campbell, and C. Cooper, "Osteoarthritis of the hip and occupational lifting," American Journal of Epidemiology, vol. 147, no. 6, pp. 523-528, 1998.
[60] T. D. Spector and A. J. MacGregor, "Risk factors for osteoarthritis: genetics," Osteoarthritis and Cartilage, vol. 12, pp. S39-S44, 2004.

[61] A. M. Valdes and T. D. Spector, "The contribution of genes to osteoarthritis," Rheumatic Disease Clinics of North America, vol. 34, no. 3, pp. 581-603, 2008. 

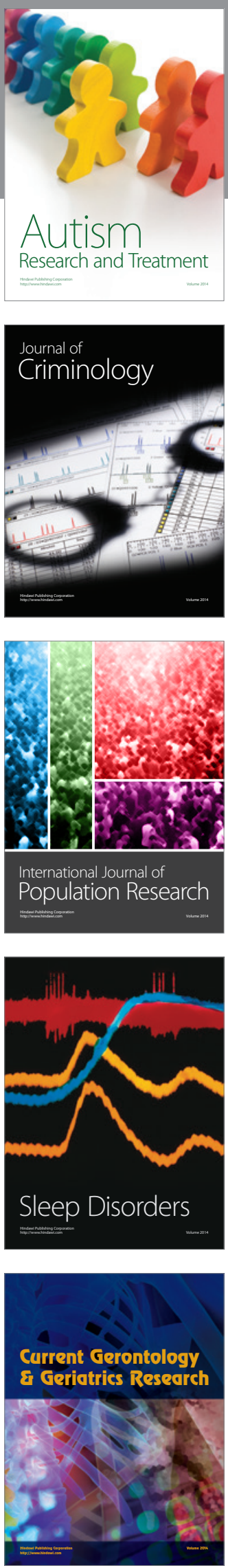
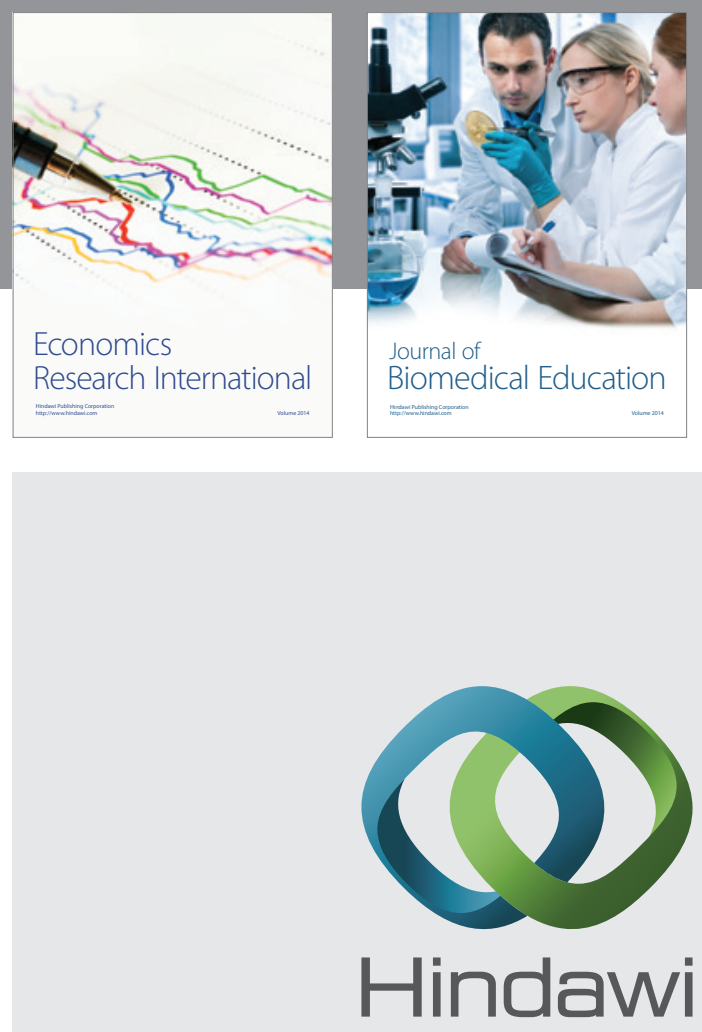

Submit your manuscripts at

http://www.hindawi.com
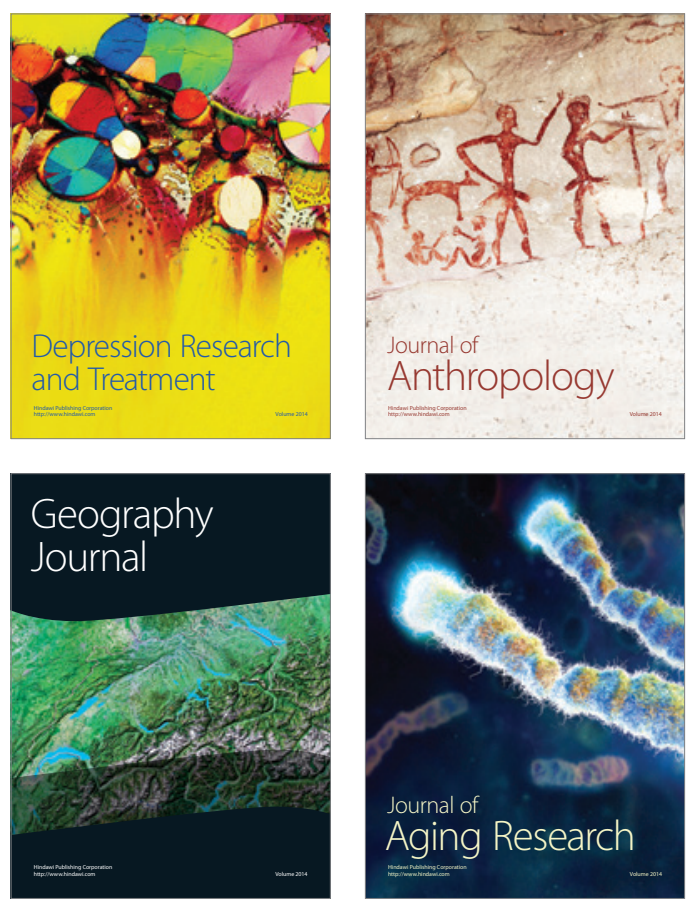
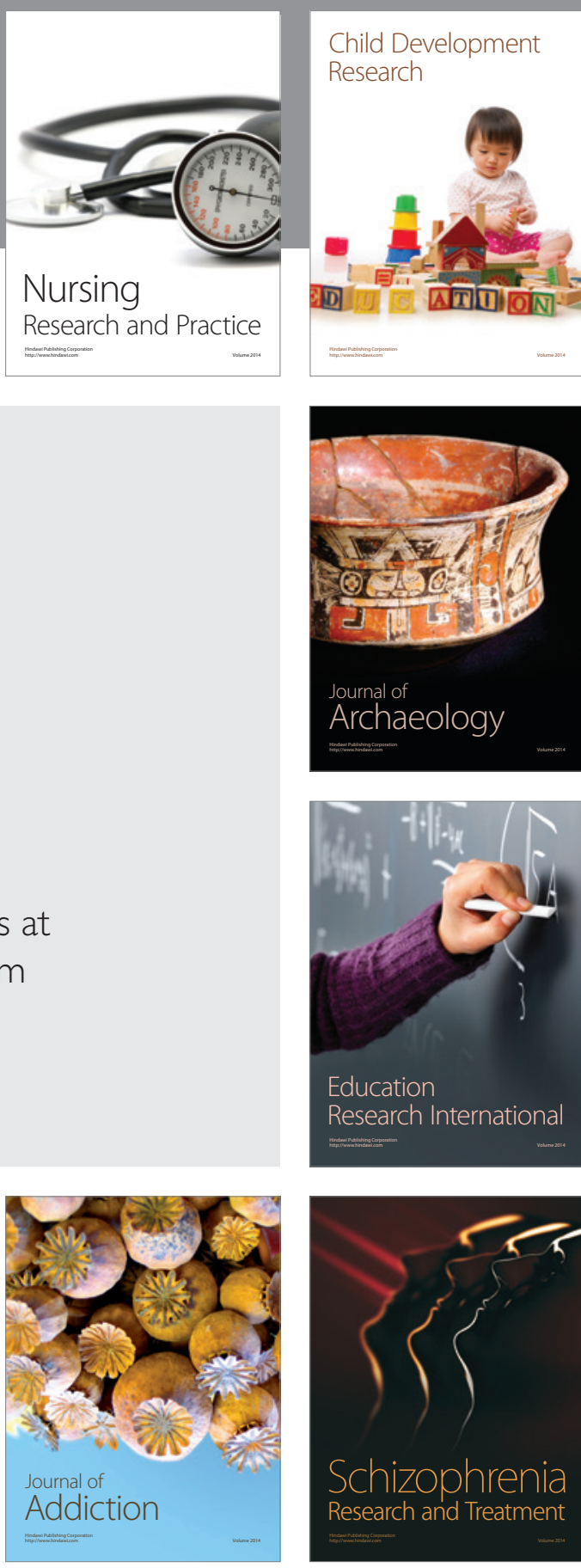

(D)
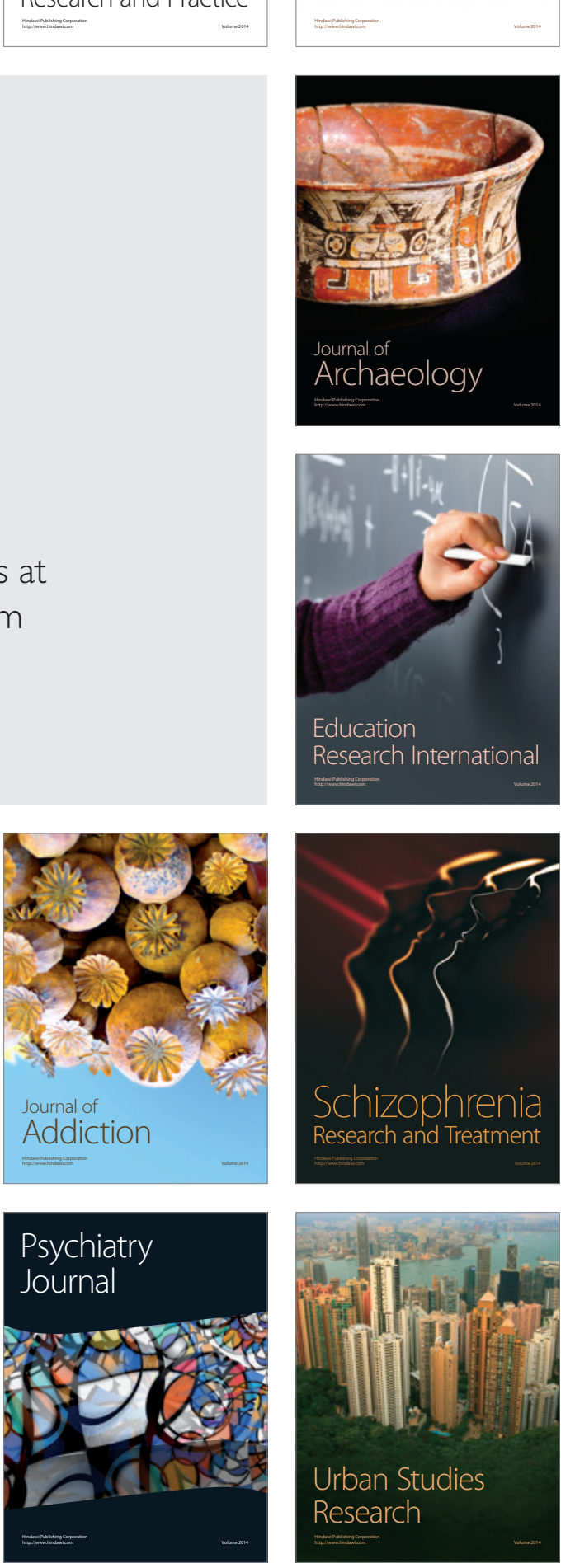